The Canadian Journal of Higher Education La revue canadienne d'enseignement supérieur

Volume XXXV, No. 4, 2005 pages 27 - 53

\title{
Learning in Medical School: Transition Issues, Strategy Use, and Self-Regulation
}

\section{DENISE REAUME \& TRACEY ROPP}

The University of Western Ontario

\begin{abstract}
This qualitative study investigated how students adapt to medical school. Thirty-six medical students completed an e-mail survey exploring the transition from pre-medical to medical education, the use of learning strategies, and self-regulated learning practices. Their responses highlighted the challenges of medical education and the learning skills that lead to the successful mastery of course demands. Respondents identified volume of information as the major transition issue. Key strategies used were establishing balance, selectively targeting information, and controlling stress. Strong metacognitive abilities and other self-regulating activities were identified. Findings indicated that while students initially found the workload stressful, the implementation of specific learning skills facilitated the adjustment to medical school. The study provides information on how high achieving students learn when confronted with new academic demands.
\end{abstract}




\section{RESUMÉ}

Cette étude qualitative a examiné comment les étudiants s'adaptent à l'école de médecine. Trente-six étudiants en médecine ont complété par courrier électronique une enquête examinant la transition de l'éducation prémédicale à l'éducation médicale, l'utilisation de statégies d'étude, et les pratiques d'auto réglementation. Leurs réponses ont mis en évidence les défis de l'éducation médicale et les compétences d'étude menant à la maîtrise des demandes de cours. Les répondants on identifié le volume d'information comme le problème de transition majeur. Les principales stratégies utilisées étaient d'établir un équilibre, de localiser sélectivement l'information, et de contrôler le stress. Des capacités métacognitives fortes et différentes activités d'auto réglementation ont été identifiées. Les conclusions de l'étude indiquent qu'au début les étudiants ont trouvé la somme de travail stressante mais que l'implantation de stratégies spécifiques d'étude a facilité l'ajustement à l'école de médecine. Cette étude fournit de l'information sur la façon dont les étudiants ayant du succès apprennent lorsque confrontés à de nouvelles demandes scolaires.

\section{INTRODUCTION}

Students selected for programs in medicine are among the highest achieving in universities. It is often presumed that these students are well equipped for the rigors of medical school. A request for learning skills programming from a Canadian medical school was the impetus for an exploration of the academic demands in first-year medicine and the skills that students found most beneficial. To this end, the initial objective of the present study was to gather information for the development of learning skills presentations for first-year medical students. This was accomplished in two ways: first and second-year students were surveyed to yield qualitative data about their learning transition and a review of the literature was conducted.

\section{Stress and Transition Issues}

As in other educational transitions such as the transition from secondary to post-secondary school, the shift from an undergraduate into a professional 
program presents unique learning challenges and adjustments which can be perceived as stressful by students. Stress among students in their initial years of medical school can be considerable (Radcliffe \& Lester, 2003); this not only has implications for mental health, but is also related to performance on exams and students' learning strategies (Tooth, Tonge, \& McManus, 1989). Medical students have reported feeling frustrated, afraid, incompetent, useless, and angry (Guthrie et al., 1995).

Researchers have found one predictor of stress among medical students to be perceptions of personal competence (Stewart, et al., 1997). Concerns about competing with people of the same or higher intellectual ability than oneself and feelings of having an inadequate background knowledge base have been found to contribute to perceptions of incompetence in medical school (Radcliffe \& Lester, 2003). Other commonly cited sources of stress have included tests and examinations (Guthrie et al., 1995; Radcliffe \& Lester) and perceived lack of guidance, including unclear learning objectives and a feeling of anonymity (Radcliffe \& Lester).

Among the many contributors to medical school stress, workload has been identified as a particularly important variable. Workload was the most frequently reported stressor in the Guthrie et al. (1995) study; respondents described difficulties keeping up with the work and not being able to catch up if they fell behind. Lee and Graham (2001) analyzed themes from medical student essays and found that many students reported feeling overwhelmed by the amount of content. As one student commented, "my expectation that I would have some time off when a test was over was totally erroneous .... I began to feel mentally exhausted ... my inclination [was] that success would only come if every spare moment was spent in the learning process” (Lee \& Graham, p. 655). One researcher asserted, "medical students are damagingly overloaded with content" (Coles, 1994, p. 3). As summarized by the Vice Dean, Education at one Canadian medical school, to facilitate the transition to medical school it is important for students to realize that it is impossible to learn everything (J. Silcox, personal communication, August 8, 2002). The strategic selection and application of learning skills is instrumental in students' adaptation to this demanding learning environment. 


\section{Learning Skills}

There are many useful paradigms that assist learning skills practitioners in their daily work assisting students. The Good Strategy User (GSU) model (Pressley, Borkowski, \& Schneider, 1987) has provided one such framework for conceptualizing effective learning. This model proposed that successful students demonstrate (a) a varied repertoire of strategies that can lead to goal attainment, (b) an awareness of when and how to use these different strategies, (c) an understanding that focused effort using effective strategies leads to success, (d) broad interests and knowledge that enhance the identification and execution of strategies, and (e) the automatic ability to implement these other components (Pressley et al.). Fleet, Goodchild, and Zajchowski (1999) offered a four-component variation of this model which described successful students as good strategy users who (a) ensure that they have appropriate background knowledge, (b) have a positive attitude about school and believe that success is within their control, (c) implement learning strategies that create a good learning environment and involve academic thinking skills, and (d) demonstrate an awareness of which strategies work best in different learning situations. A key consideration in the present investigation was the relevance of these components to medical education.

Three categories of studies on learning in medical school were identified: learning approaches, the nature and extent of self-directed learning, and specific learning strategies. Newble and Entwistle (1986) described three approaches to learning that involve learning style and context: surface, deep, and strategic. Surface learners were described as rote learners who try to remember isolated pieces of information; these learners are motivated by a desire to finish a course or task or to avoid failing. According to Newble and Entwistle, the learning outcome is either very limited or superficial understanding, although substantial factual knowledge may be known. Researchers have found the use of surface approaches to increase as trait anxiety (e.g., a task that creates anxiety, such as an upcoming exam) increases (Tooth et al., 1989). Surface learning has also been associated with a perceived heavy work load (Tan \& Thanaraj, 1993), a key characteristic of medical studies.

In contrast, deep learners were described as those who always work 
to understand the course material, either because of being interested in the content or because they see the long-term relevance of acquiring the knowledge (Newble \& Entwistle, 1986). Students using this learning approach often spend significant time in independent study. In the Tooth et al. (1989) study of medical students, deep learning was not related to exam performance, although a positive relationship had been established in other studies of university students in general (Thomas \& Bain, 1982).

The third type of learners, those labeled by Newble and Entwistle (1986) as being strategic, show flexibility in their learning style, choosing either deep or surface approaches depending on the particular learning task. The researchers indicated strategic learner motivation primarily derives from wanting to achieve high marks, resulting in the use of resources and strategies to help achieve this outcome. The most successful students have usually been those adopting the strategic approach (Newble \& Entwistle). Unlike exclusive use of deep learning, strategic learning has been positively correlated with exam success among medical students (Tooth et al., 1989). The ability to choose appropriate approaches and strategies depending on specific learning tasks demonstrates metacognitive strengths.

More encompassing than the way students think about their learning, self-regulation has been described as, "the self-directive process through which learners transform their mental abilities into task-related academic skills .... whether the learner displays personal initiative, perseverance, and adaptive skill” (Zimmerman \& Schunk, 2001, p. 1). Hence, selfregulation involves motivational, behavioural, and metacognitive components (Zimmerman \& Schunk). Evensen, Salisbury-Glennon, and Glenn (2001) provided an examination of the strategic learning and selfregulation activities of six medical students. These authors cited the ability to manage large volumes of information in short periods of time as a key learning strategy. Other transitional challenges in the students' quest for self-regulation included abandoning thoughts that course content was disconnected and trivial, realizing it was harder to cram and catch up if one fell behind, needing to compensate for a lack of a science background, and dealing with a "collective anxiety" in the class (Evensen et al.). Enhancing self-directed learning and responsibility of students were cited as important considerations for many medical schools (Wolf, 1994). 
The use and effectiveness of specific learning strategies as applied to the medical school setting sheds light on how high-achieving students learn. In terms of note-taking strategies, Farrand, Hussain, \& Hennessy (2002) found that mind mapping techniques improved medical students' memory and recall of written information. Other strategies included organizing a note-taking pool and working in groups (Evensen et al., 2001). In their exploration of strategies new medical students used to cope with the transition, Evensen et al. identified organizing content by starting with the "big picture" and then adding details into the broad framework. The importance of this learning strategy, referred to as information structuring (Fleet et al., 1999), may be even greater in medical school than in undergraduate studies because of the substantial volume of information to be learned. In terms of exam performance, success on an objective structured clinical exam was related to time spent studying and academic achievement in prior years of study (Mavis, 2000). Although recent studies have begun to explore specific learning strategies, more research is needed to investigate the strategies employed by successful medical students and to see how existing learning paradigms apply to medical students. The aims of the present qualitative investigation were to provide an exploration of the transition issues of medical students, the learning strategies used in medical school, and the self-regulated learning practices of medical students.

\section{Participants}

\section{METHOD}

A total of 36 medical students (24 in first year and 12 in second year) volunteered to participate. Five of the seven top achieving students in first and second year - three males and two females - were among the participants; gender is not available for other participants. All 36 respondents were high achieving students who had a minimum 3.60 grade point average in their undergraduate programs prior to entering medical school.

\section{Procedure}

A survey was developed to explore transition issues, strategy use, and self-regulated learning practices of medical students (see Appendix). Open-ended questions were devised to solicit information that would be 
helpful to learning skills practitioners in developing programs for this population of students. The survey was designed to be short enough so as not to be onerous given the heavy demands of the medical program but long enough to generate comprehensive information on the first-year medical school experience.

The survey and its rationale were sent by e-mail to the 258 students in their first and second years of medical school at The University of Western Ontario in March 2003. Second-year students were included to provide a more comprehensive perspective of the first-year experience. An e-mail format was used primarily to provide busy medical students with an efficient way to respond. In addition, compared to other types of surveys, e-mail surveys have been found to elicit longer responses to open questions (Paolo, Bonaminio, Gibson, Patridge, \& Kallail, 2000). The email explained that their insights would contribute to the development of academic supports. Students were informed that participation was voluntary, that their responses would not be forwarded to their faculty, and that any materials incorporating their responses would not identify them without their permission.

The survey was sent after students had written three of four sets of exams. This was to ensure that students had experience in medical school to draw upon (cited as an important factor in Martenson \& Brattebo, 1992) and had received feedback on their academic performance to evaluate whether or not they had to modify their pre-medical education approach to learning. It was initially sent to seven students - five in first year and two in second year - identified by the Faculty of Medicine as being the top achievers in their years. This was done to ensure that future presentations developed for this population could incorporate observations from students who were especially successful in medical school. A week later the survey was sent to all first and second-year medical students. Students emailed their responses directly to the authors. The most common transition issues and strategies were identified as those with frequencies within $50 \%$ of the top response. For example, all responses with frequencies of 15 and greater were included if the top response was mentioned 30 times. Representative responses were selected to illustrate the themes and provide examples specific to the medical school experience. 


\section{RESULTS}

Survey responses revealed some medical school experiences that were idiosyncratic and many that were shared. Some of the outliers included a second-year student's claim that massage therapy and a \$300 ergonomic chair were among the most significant factors in exam success, and a top first-year student's observation that he loved to procrastinate and that, "To be honest, compared to my last year of undergrad, medicine is a breeze.” Given the objectives of the study, the most significant results were those that reflected the typical experience of learning in medical school. Common themes regarding transition issues, learning strategies, and self-regulated learning are summarized below.

\section{Transition Issues}

Transition issues were assessed in questions asking students (a) to describe the most significant differences between their pre-med university education and first-year medicine and (b) what they would do differently if starting medical school the following September. Table 1 lists transition issues that received more than one mention. The four most common issues identified were increased volume of information, increased time pressures, less competition with more support, and more stress.

\section{Increased volume of information.}

Increased workload was the difference most often identified by respondents. One student summarized this experience with the observation, "The amount of material covered in lectures increased exponentially." The adjustment to an increased volume rather than more difficult content was evident in the following responses: "It's not that the work is necessarily harder than undergrad, it's just that there is much more material covered," and "The biggest difference is that in medical school we're responsible for a much larger volume of material, but in considerably less detail (individual exam questions are easier, but exams cover vast amounts of information, so exams are actually more difficult).” 
Table 1

Transition Issues Reported by Medical Students

\begin{tabular}{lc}
\hline \multicolumn{1}{c}{ Type of issue } & Frequency \\
\hline Increased volume of information & 22 \\
Increased time pressures & 17 \\
Less competition/more support & 16 \\
More stress & 11 \\
Lack of background knowledge & 7 \\
More time in class & 7 \\
Fewer assignments to hand in & 3 \\
Less emphasis on grades & 3 \\
Expectation that learn some topics on own & 2 \\
Expectation that information be applied & 2 \\
New exam format & 2 \\
\hline
\end{tabular}

Note. Frequency values represent each mention of a transition issue.

Only issues with frequencies $>1$ are included.

\section{Increased time pressures.}

The need for better time management in medical school compared with pre-med education was a related transition issue identified. Students said, "In pre-med I could cram. There's just too much material to do that now," and "I find that it's important to stay caught up with work in medical school, whereas during undergrad I could wait until a week before the test before even beginning to do reading/studying." One student wrote, "In premed, time is typically abundant. There's plenty of time for extracurricular activities and studying.... Time becomes very precious [in medical school] as there is much less of it comparably."

\section{Less competition with more support.}

A recurring observation was that there was the support of a community in medical school. This is illustrated in the comment, "The biggest difference I found was the sense of camaraderie that was absent in undergrad.” One student described pre-med as "way more competitive" than medical school where "it feels a lot more like 'everyone's in this thing together."” Another wrote that in medical school, "The atmosphere is much more 
relaxed. People are not as competitive. Marks are not all that important and people seem genuinely willing to help one another out.” As well, responses supported one student's observation that "The administration, lecturers and professors are much more supportive in medical school than they were in my pre-medical education.”

\section{More stress.}

Stress associated with the transition to medical school was also evident. One student wrote, "Most of our class got sick the first semester because we didn't know how to adjust to the high volume of material when given so much less independent time as compared to undergrad." Another recommended that new students, "Relax! I think the first set of exams were the most stressful for everyone because we didn't really know what to expect." Future professional responsibilities added to this pressure as is evident in the observation that the "volume of information is greater and often seems very important as it may be used to save lives." Responses indicated that this stress moderates with time. A student remarked that "the first set of exams just sneak up on you....You become better at pacing yourself as you go. Furthermore, you simply get used to the change in workload.” If he were entering medical school with the experience he had at the time of the survey, a top first-year student indicated that he “wouldn't get so worked up about exams.... it's really not as hard as people seem to think it is, so if you did well in undergrad, you'll do well in med school.” Another source of stress at the outset was lack of confidence. A student had this advice for new students: "Don't be intimidated by the other students in your class. It will seem at first as if they're all more intelligent, interesting, dynamic, etc. than you, but it’s not true. They just talk about themselves a lot.”

\section{Lack of background knowledge.}

While not one of the main issues identified, lack of background knowledge is noteworthy. Prior background knowledge would not be a transition issue for all students, however responses suggest that the challenge is significant for those who lack a comprehensive science background. This is conveyed in the following comment: 
I truly believe that some basic science background prior to coming to medical school is a HUGE asset. The volume, speed and frequency of testing is so rapid especially in the first two quarters of year 1 , having a background (or at least being familiar) with some anatomy or biochemistry or immunology, goes a long way in making your life easier.

Other comments reinforced the position that demands were significantly greater for students lacking certain science programs. One student wrote, "I had never done anatomy before, so I felt I was totally lost in the new language." Another wished she had taken courses in Anatomy, Biochemistry, and Physiology prior to coming to medical school because, "we often must learn a semester's worth of undergraduate material in barely 2 weeks! It's do-able, but definitely these intro courses would at least make the initial influx of material at least more familiar and thus less intimidating."

\section{Learning Strategies}

The use of learning strategies in medical school was investigated in three questions on managing time, managing volume, and preparing for exams and writing multiple-choice tests.

\section{Time management strategies.}

The two most common strategies to manage time were establishing a balance and pacing. Time management strategies identified by respondents are listed in Table 2.

The emphasis on balance and pacing are reflected in a top student's response:

I make a conscious effort to ensure that I devote time to family, exercise and extra-curricular activities as well. It's only recently that I've come to realize that I'm actually far more productive when I have a good balance between the social and academic aspects of my life.

This theme was echoed in other responses, for example, "Make time for medical and non-medical friends, get involved, and have fun," and "Sleep. 
Table 2

Strategies Reported by Medical Students to Manage Time

\begin{tabular}{lc}
\hline \multicolumn{1}{c}{ Strategy } & Frequency \\
\hline Establish a balance & 30 \\
Pace self & 28 \\
Use time management tools (schedules, etc) & 14 \\
Prioritize & 11 \\
Be efficient/don't waste time & 4 \\
Stick to plan/be disciplined & 4 \\
\hline
\end{tabular}

Note. Frequency values represent each mention of a strategy to

manage time. Only issues with frequencies $>1$ are included.

Workout. If you don't, then you can spend an hour reading a page that should take 5 minutes." Comments about pacing included, "Studying an hour or two each day makes it easier to absorb all the information," and "Pacing is most important to remain balanced and sane."

\section{Strategies to manage volume.}

The three strategies most often cited to manage the heavy volume of information were selectively targeting information, preparing for and attending lectures, and repetition and review of material. Responses are summarized in Table 3.

Most respondents emphasized the need to selectively target information in order to manage the heavy volume of information, as reflected in the comment, "There's no way you can read/do everything you are supposed to, so I try and hit the ones that are either most interesting to me or seem most important to a general understanding of medicine.” Learning for their future profession rather than grades was a selection criterion that others also identified as illustrated in the comments, "[I] try to concentrate on what I think will be important in the future and concentrate less on the things that will only be tested on the exam and seem to be of more minor importance for the future," and "I think it's important that we know the big concepts so that we can build on this foundation as our careers progress."

While not all respondents advocated going to class - one student wrote, "Much to the chagrin of the faculty, I find that self-directed learning in certain courses proves a lot more useful than spending hours sitting 
Table 3

Strategies Reported by Medical Students to Manage Volume

\begin{tabular}{lc}
\hline \multicolumn{1}{c}{ Strategy } & Freqency \\
\hline Selectively target information & 24 \\
Prepare for and attend lectures/labs & 17 \\
Repetition and review of material & 14 \\
Activate background knowledge & 3 \\
Learn as material unfolds/ first time through & 3 \\
\hline
\end{tabular}

Note. Frequency values represent each mention of a strategy to manage volume. Only issues with frequencies $>1$ are included.

and falling asleep in lectures" - many more found class attendance an important aspect of managing the heavy course volume. One student attended all lectures to determine "if any additional reading is necessary. I usually only do additional reading if I do not understand a concept or if I want a broader understanding of what is presented." Another was more direct: "I manage the heavy volume of material by attending every lecture, pre-reading the notes before class (usually), and reading the notes after class well in advance of exams. Then at exam time, I only have to cram the details, not the major concepts."

Repetition and review ranked third among strategies to manage volume. One student noted, "I try to go over what I learn on any given day the same day. Repetition is key.” Another student concluded, "The more I review, the better I master the information.” A top student wrote, "I try to work through material several times before an exam, gaining more concepts and committing information to memory each time through.”

\section{Preparing for and writing multiple-choice exams.}

Strategies for preparing for exams focused on controlling stress, pacing, prioritizing, maintaining a balance, repetition of material, and using recommended methods for writing multiple-choice exams. Table 4 lists responses.

Strategies to control stress included seeking peer support and putting exams in perspective. The support of peers facilitated exam preparation. Students observed the benefits of studying at school, "because many other 
Table 4

Strategies Reported by Medical Students to Prepare for and Write Exams

\begin{tabular}{lc}
\hline \multicolumn{1}{c}{ Strategy } & Frequency \\
\hline Control stress: peer support and perspective & 23 \\
Pace self & 22 \\
Prioritize & 18 \\
Maintain a balance & 16 \\
Repetition of material & 14 \\
Use methods for writing multiple-choice exams & 13 \\
Avoid stressed peers & 3 \\
Study at school to lessen distractions & 3 \\
Be disciplined & 2 \\
Make summary notes & 2 \\
\hline
\end{tabular}

Note. Frequency values represent each mention of a strategy to prepare for and write exams. Only issues with frequencies $>1$ are included.

people from your class are there so you don't feel so bad being cooped up in the library all day. Also it helps to bounce ideas and study strategies off other students." One student indicated a preference for studying at school especially at exam time, observing, "It's quite fun to be surrounded by friends and classmates who are all on the same page. It becomes very much like the moments before an important sporting event - adrenaline is pumping and we're eager to show our stuff." As summarized in the following response, a strategy that helped control stress during exam periods was, "Putting things into perspective; the objective is to learn and not to get honours. A pass is acceptable!!”

Pacing was also identified as an important strategy in exam preparation. One student wrote, "Begin preparing earlier rather than later.... I have found that a good night's sleep before the exam is much better than cramming all night long." Another student remarked,

I am a firm believer in spacing out your studying over the days because I find that if I study something and then sleep on it for a few days and return to it, I retain so much more than I would if I were to spend all my time during the one day.

Prioritizing and maintaining a balance were the next most common 
strategies identified as contributing to exam success. One student prioritized by "thinking actively about what might be tested. Looking for lists, exceptions, emphasized points.” A second-year student recommended focusing on "the common concepts between a group of diseases rather than the specific diseases themselves, e.g., the common thread between all the congenital valvular diseases.” Establishing a balance with breaks and adequate sleep were also identified as being important to exam preparation. Students wrote, "Being organized and making sure I eat and sleep well and pursue activities (like sports) outside of school to refresh myself and give myself a mental break have really helped," and "I try not to get too stressed out, I still exercise and try to eat well, and I try to get as much sleep leading up to exams as possible.”

The importance of repetition and pacing resurfaced in responses about test preparation. One student's study method was "Repetition of material. By the third and fourth time through, I begin to feel quite comfortable with it.” A number of students also recommended specific methods for writing multiple-choice tests; these suggestions reflected the general recommendations outlined by Fleet et al. (1999) to cover the alternatives, carefully read the question, and predict an answer. General strategies were also apparent in respondents' advice that students use the process of elimination to narrow choice and start with questions they know to build confidence. A strategy applied to medical school exams was offered in this recommendation: "look for anything that says "always", "never", and generally rule them out. There are very few instances in medicine where something is definitely ruled in or out.”

\section{Self-regulation}

Self-regulated learning practices were evident in numerous responses. Participants demonstrated strong metacognitive abilities in answers that revealed a keen sense of what changes students had to make when confronted with the realities of medical school and what strategies could best help them achieve these outcomes. The following response summarized this experience:

Prior to coming to medical school, I was always a last minute, cram it all, late-nighter kind of guy. While this may have gotten a 
student into medical school, you need to change. There is just too much volume. Thus one needs to handle the information in small chunks over a period of time in order to understand and remember the material.

Another student discussed the importance of "finding a style that helps you learn the material best (i.e., some people read the material many times quickly, other people prefer to read it once thoroughly; solitary vs. group studying)... it's a very individual choice.” One student cautioned, "Memorizing all the information is not useful if you don't know how to apply it or the importance it will have later on,” exhibiting a knowledge of the learning objective.

Students' responses emphasized not only an awareness of which approaches worked best, but showed a high degree of motivation. Perseverance was identified as an important aspect of mastering course content. For example, a top student recalled a faculty member's advice that while the volume of information in medical school is overwhelming, important details will be taught repeatedly: "I recall this advice when I am frustrated that I cannot remember things from blocks in the past; with repetition over the four years, I will eventually remember the key points." Students were motivated by the knowledge that they would "use this information in the future rather than learning just to pass the course." Being motivated so as not to appear incompetent or foolish was captured in the following response: “The profs aren’t trying to find out who knows the most trivia, they just want to make sure that they are sending you out there with the right info, so that you don't feel like a doufous come clerkship."

Self-regulating behaviour was also evident in survey responses. Students purposefully determined courses of action, as is apparent in the response, "I find that I learn best when I get exposed to the topics in a variety of different ways. This is one of the reasons... looking on the web is a really important skill.” Another student encouraged implementing the "style of learning [that] works best for an individual. If teaching, then arrange to teach someone who likes to listen. If visual, then draw concept maps.” Many respondents indicated the need to adjust the style of learning depending on the context. A second-year student wrote, "Ignore almost 
anything taught by people other than clinicians, leave pathology until the week before the exam because it's all just info you have to cram into shortterm memory." Another student described preparing for exams with the observation, "some stuff that I think/know is more important I make an effort to know very well, some stuff I just make sure that I've read it over a couple of times going into the exam so I'll recognize multiple choice answers."

The response by a top second-year student encapsulated the key characteristics of self-regulated learning: she wrote, "In my pre-medical education I diligently read any and all recommended texts, readings and websites completely and thoroughly. I realized early in first year that I would have to change my strategy - there is simply too much material to read!” This statement clearly demonstrates metacognition in that she recognized the need to change her learning approach. The motivational component of self-regulated learning is evident in the development of a plan, and the behavioural component is shown in the subsequent action, as described below:

I focus on material presented in the notes, and use supplementary material only for concepts that are not clear. In addition, I usually read a chapter from a general medicine textbook (Cecil's) at the beginning of each block to refresh concepts from first year. The advantage of using the medicine text is that it tends to focus on clinically-relevant concepts. If I come across something while studying that I know I have studied in the past but cannot remember very well, I review the concept.

In summary, findings provide an understanding of the transition that new medical students undergo, the learning strategies they find to be most useful, and the self-regulated learning activities that help them adapt to the demands of medical school.

\section{DISCUSSION}

The findings suggest that there are important transition issues for students moving from pre-medical to medical education. Even though participants had achieved substantial academic success to gain entry to medical school, they initially experienced stress which was most associated 
with the considerable increase in the volume of course information. Specific learning strategies and self-regulation helped the students adapt to this new learning environment. In their responses to the survey, students indicated that they moved from feeling "overwhelmed with how much we don't know" to feeling that the volume "is a lot, but everyone adapts."

The present study confirms the results of previous research citing workload to be a key issue in medical school (Coles, 1994; Guthrie et al., 1995; Lee \& Graham, 2001). Furthermore, this study extends previous research by investigating the strategies students use to manage this volume and to deal with the accompanying increased demands on time. These included being selective in choosing the most important information, preparing for and attending lectures, and engaging in regular review.

A heavy workload places significant demands on time management (Wolf, 1994). Students in the present study indicated that establishing balance and pacing were important time management practices in medical school. Students who achieve balance are able to enhance academic productivity, enjoy learning, and engage in self-care practices. Given that stress has been identified as a common experience of new medical students (Radcliffe \& Lester, 2003), helping medical students achieve a balance may be an effective way of decreasing stress levels. Implementing time management instruction or support could be a helpful addition to medical school programs, as long as the unique pressures of medical education are understood and acknowledged.

Students demonstrated effective understanding and use of various general learning skills. For instance, some commented on the importance of looking for common themes between groups of concepts; this exhibits an understanding of the use and importance of information structuring. Structuring helps students understand and apply information (Fleet et al., 1999), which is in accordance with Newble and Entwistle's (1986) classification of a deep approach to learning. Other indications of a deep approach to learning occurred when students expressed wanting to learn information for themselves rather than simply for a high average. Many students also discussed strategies indicative of the strategic approach discussed by Newble and Entwistle, such as thinking about what information was likely to be tested and prioritizing time and topics accordingly. 
The present study also investigated strategies that medical students used in test preparation and test-taking. Student responses to questions about writing multiple-choice exams were found to be consistent with effective test-taking strategies outlined by Fleet et al. (1999). This suggests that medical students generally enter medical school knowing about and using effective multiple-choice strategies. Medical students may benefit from reassurance that specific learning strategies are transferable to the medical school context. It is noteworthy that one top first-year student wrote that the worst advice she received was that "the way you studied in undergrad won't work for medicine.” While other respondents clearly indicated the need to change their study approach to adapt to medical school, the degree of change required may depend on the strength of students' skills before entering medical school. The implication is that the emphasis placed on the differences between pre-med and medical education may contribute to new medical students feeling as though they lack the skills for academic success in their new program, when in reality some may have developed the skills that contribute to success in medical school in their prior undergraduate program. This warrants investigation, especially given earlier studies have found that feelings of incompetence have been identified as a predictor of stress in medical school (Radcliffe \& Lester, 2003; Stewart et al, 1997). Furthermore, as discussed in Fleet et al., having a positive attitude about school and believing that success is within one's control is one of the components of being a successful student in general. Future research could explore the relationship between grades in first-year medicine and learning strategies prior to entering medical school.

Survey results demonstrated the various components of the GSU model as proposed by Pressley et al. (1987) and Fleet et al. (1999). In their responses, students clearly articulated using various strategies to attain their goals and knowing when to use these different strategies. This was most evident when they commented on the differences between how they managed, applied, and remembered information in pre-med versus medical school. These skills were also demonstrated within the medical school context itself, such as when a student commented, "I usually only do additional reading if I do not understand a concept or if I want a broader understanding of what is presented.” Some respondents noted 
that having a limited science background prior to medical school posed an extra challenge in their quest for continued success. This reinforces the importance of background information for academic achievement as emphasized by Fleet et al. and the role it can play in fostering feelings of competence (Radcliffe \& Lester, 2003).

Another component of the GSU model is understanding that using effective strategies with focused effort contributes to success; students demonstrated this in their repetition of material and in using peers as motivation for discussing ideas and learning strategies. Participants also commented on broad interests and knowledge that enhanced their strategy use, making suggestions such as working with peers and finding ways to expand a weak science background. Having the automatic ability to implement the other GSU components is the fifth component of the model; future research could assess the ease with which medical students implement the other components.

Findings demonstrated many components of self-regulated learning. One student in particular captured all three self-regulation components when identifying the differences between pre-med and first-year medical school. Her metacognitive abilities were highlighted in her recognition of the necessity to change her approach, motivation was demonstrated in the development of a plan, and she used specific strategies to attain mastery of material. Future research could examine the extent to which medical students in general demonstrate these metacognitive, motivational, and behavioural components of self-regulation and compare whether there are differences between higher and lower achieving students. While data on these different populations were gathered in the present study, the limited sample size makes comparisons difficult. It would also be important to determine whether these strategies are learned primarily through prior educational experiences or whether they are context-specific and, therefore, need to be adapted and re-learned when confronted with a transition to a new learning environment. Furthermore, investigating whether these are relatively stable characteristics or whether they change significantly from the start of medical education through to upper years would help in the design and implementation of learning skill interventions for this population. One of the underlying issues in theories of self-regulated 
learning is how individuals acquire self-regulation capacities (Zimmerman \& Schunk, 2001). Researchers have begun to conceptualize the mechanisms contributing to self-regulation through the creation of preliminary models (e.g., Evensen et al., 2001). Future exploration of the questions posed above will lend insight into if and how self-regulation can be effectively taught or supported in medical school.

An interesting dissimilarity surfaced in findings regarding the social environment in medical school. Radcliffe and Lester (2003) found that competition among medical students contributed to feelings of incompetence. In the present study, when students were asked about the most significant differences between their pre-medical and medical education, a common response was that there was a considerable decrease in the amount of competition in medical school. Participants used words like "community" and "camaraderie" to describe this experience and identified the marking system in medical school as being the key reason for this change. This view is summarized in the response, "With the pass/ fail/honours system, there was far less competition between classmates than in my pre-med degree. Students are encouraged to study and learn to be clinicians, rather than to simply achieve a high grade-point average.” Given that researchers have found feelings of personal competence to be a predictor of stress (Stewart et al., 1997), this discrepancy suggests that medical schools can help students better manage stress by de-emphasizing marks.

The current findings also offer an alternative interpretation to the motivation for employing a strategic approach to learning. The strategic movement between surface and deep learning approaches has been identified as being positively correlated with medical students' exam success (Tooth et al., 1989). Newble and Entwistle (1986) suggested that the desire for high marks was the primary motivation of strategic learners. While high marks may be an outcome of a strategic learning approach, the present study proposes that another significant motivation for medical students is having to manage the high volume of information. Participants strongly asserted that it was not possible to master all course material; a strategic learning approach enabled students to employ deep learning for information that seemed, as one student noted, the "most important to a 
general understanding of medicine” and surface learning for information deemed minor. Students with perfectionistic tendencies may find making these distinctions difficult; for example, one student indicated she struggled with the recommendation that students focus on the big picture because, "I would want my doctor to know the details.” While studies have investigated relationships between perfectionism, stress, and performance (Enns, Cox, Sareen, \& Freeman, 2001; Lievens, Coetsier, De Fruyt, \& De Maeseneer, 2002), future studies could explore the relationship of these variables to learning approaches.

There are two limitations to the present study. Although the response rate among the top achieving students was $71 \%$, the overall response rate of $14 \%$ makes it difficult to know whether or not the responses are representative of the medical school experience. It is important to acknowledge the possibility of a self-selection bias. Students who responded may have had greater interest in learning skills than average and possessed particularly strong metacognitive abilities. However, it is noteworthy that despite the time intensive nature of medical school, 35 of the 36 respondents provided detailed, articulate, and insightful responses. As well, the main objective was to solicit information in order to develop learning skills programming for medical students. The concurrence of responses with the literature and the high response rate among top achievers reassured the practitioners that responses reflected good learning practices. Nevertheless, future research with a larger sample size drawn from a range of medical schools would assist in knowing whether the present findings can be generalized to the medical student population. The procedure for distributing surveys by email should also be reassessed in future research; a review of e-mail survey use found that response rates have been decreasing over time (Sheehan, 2001). Sending a pre-notification or a reminder e-mail may have helped the overall response rate (Sheehan) and should therefore be considered when using e-mail surveys.

A second limitation stems from the fact that the initial objective of the survey was not formal research but the development of a learning skills presentation series for first-year medical students. To ensure that respondents considered the issue from a broad perspective, the third 
question of the survey stated, “Time management involves being productive and establishing a healthy balance.” Although this may have influenced responses, students provided sufficient elaboration to warrant inclusion of the question in the study.

In conclusion, the present study investigated how students adapt to the academic demands of medical school. Exploratory in nature, this study provides information on the first-year medical school experience and how high achieving students learn once admitted to this intensive program. Findings generally support earlier studies and identify possible future research initiatives. While there are parallels between the transition from high school to university and pre-medical education to medical school, the experience of medical students is particularly interesting in that they have demonstrated significant success as learners at the post-secondary level prior to entering this professional prog how high achieving students manoeuvre the challenges of medical school provides practitioners with useful information for the development of support programs and identifies learning skills that are perceived as being particularly important to academic success. 


\section{NOTES}

The authors would like to thank the students in the classes of 2005 and 2006 at Western's Schulich School of Medicine who participated in this study. Despite the substantial demands already on their time, their survey responses were thorough and thoughtful.

\section{Author contact information}

Denise Reaume

Student Development Centre

The University of Western Ontario

London, Ontario

N6A 3K7

dreaume@uwo.ca

Tracey Ropp

Student Development Centre

The University of Western Ontario

London, Ontario

N6A 3K7

tracey@sdc.uwo.ca 


\section{REFERENCES}

Coles, C. (1994). Medicine and stress. Medical Education, 28, 3-4.

Enns, M. W., Cox, B. J., Sareen, J., \& Freeman, P. (2001). Adaptive and maladaptive perfectionism in medical students: A longitudinal investigation. Medical Education, 35, 1034-1042.

Evensen, D. H., Salisbury-Glennon, J. D., \& Glenn, J. (2001). A qualitative study of six medical students in a problem-based curriculum: Toward a situated model of self-regulation. Journal of Educational Psychology, 93, 659-676.

Farrand, P., Hussain, F., \& Hennessy, E. (2002). The efficacy of the 'mind map' study technique. Medical Education, 36, 426-431.

Fleet, J., Goodchild, F., \& Zajchowski, R. (1999). Learning for success: Effective strategies for students. Toronto: Harcourt Brace.

Guthrie, E. A., Black, D., Shaw, C. M., Hamilton, J., Creed, F. H., \& Tomenson, B. (1995). Embarking upon a medical career: Psychological morbidity in first year medical students. Medical Education, 29, 337341.

Lee, J., \& Graham, A. V. (2001). Students' perception of medical school stress and their evaluation of a wellness elective. Medical Education, 35, 652-659.

Lievens, F., Coetsier, P., De Fruyt, F., \& De Maeseneer, J. D. (2002). Medical students' personality characteristics and academic performance: A fivefactor model perspective. Medical Education, 36, 1050-1056.

Martenson, D., \& Brattebo, G. (1992). An introductory 'survival course' for first-year medical students: A brief account of the course. Medical Education, 26, 340-342.

Mavis, B. E. (2000). Does studying for an objective structured clinical examination make a difference? Medical Education, 34, 808-812.

Newble, D. I., \& Entwistle, N. J. (1986). Learning styles and approaches: Implications for medical education. Medical Education, 20, 162-175.

Paolo, A. M., Bonaminio, G. A., Gibson, C., Patridge, T., \& Kallail, K. (2000). Response rate comparisons of e-mail and mail distributed student evaluations. Teaching and Learning in Medicine, 12, 81-84. 
Pressley, M., Borkowski, J. G., \& Schneider, W. (1987). Cognitive strategies: Good strategy users coordinate metacognition and knowledge. Annals of Child Development, 4, 89-129.

Radcliffe, C., \& Lester, H. (2003). Perceived stress during undergraduate medical training: A qualitative study. Medical Education, 37, 32-38.

Sheehan, K. (2001). E-mail survey response rates: A review. Journal of Computer-Mediated Communication, 6. Retrieved April 29, 2005, from http://jcmc.indiana.edu/vol6/issue2/sheehan.html

Stewart, S. M., Betson, C., Lam, T. H., Marshall, I .B., Lee, P. W. H., \& Wong, C. M. (1997). Predicting stress in first year medical students: A longitudinal study. Medical Education, 31, 159-162.

Tan, C. M., \& Thanaraj, K. (1993). Influence of context and preferred learning environments: Approaches to studying physiology. Medical Education, 27, 143-159.

Thomas, P. R., \& Bain, J. D. (1982). Consistency in learning strategies. Higher Education, 11, 249-59.

Tooth, D., Tonge, K., \& McManus, I. C. (1989). Anxiety and study methods in preclinical students: Causal relation to examination performance. Medical Education, 23, 416-421.

Wolf, T. M. (1994). Stress, coping and health: Enhancing well-being during medical school. Medical Education, 28, 8-17.

Zimmerman, B. J., \& Schunk, D. H. (Eds.). (2001). Self-regulated learning and academic achievement: Theoretical perspectives ( $2^{\text {nd }}$ ed.). Mahwah, NJ: Lawrence Erlbaum Associates. 


\section{APPENDIX}

\section{Survey of Medical Students}

1) What were the most significant differences that you experienced between your (i) pre-med university education and first year medicine and (ii) your first and second year in medical school?

2) Considering what you now know about learning in medical school, if you were starting Year 1 this Fall what would you do differently?

3) Time management involves being productive and establishing a healthy balance. How would you rate your time management skills? What approach do you use to manage your time?

4) How do you manage the heavy volume of information in lectures and readings?

5) In the days leading up to exams and while in exams, what strategies have contributed most significantly to your success? What specific suggestions do you have regarding multiple-choice exams?

6) What is the best and worst advice that you received about learning in medical school?

7) Are there any self-help books and web sites for medical students that you would recommend?

8) Other observations not addressed in the earlier questions that may benefit first and second year medical students. 